\title{
Experimental Study of Compaction Effects and Proportion of Expansive Soil Improved by Ionic Soil Stabilizer
}

\author{
Xuesong $\mathrm{Lu}^{1, \mathrm{a}}$, Cunfeng $\mathrm{Xia}^{2, \mathrm{~b}}$ \\ ${ }^{1}$ Huanggang Normal University, Huanggang, Hubei 438000, P.R. China \\ ${ }^{2}$ Huanggang Academy of Urban Planning \& Design, Huanggang, Hubei 438000, P.R. China \\ a'E-mail: hglqy@126.com, ${ }^{\mathrm{b}} \mathrm{E}-\mathrm{mail}: 275465587 @ q q . c o m$
}

Keywords: ISS; expansive soil; maximum dry density; soil particle density; adsorbed water Abstract: Research and development of fast, economic and effective controlling method and theory of engineering has always been the focus of engineering construction for all the countries. In this research, a kind of Ionic Soil Stabilizer (ISS for short) is used to improve expansive soil. Based on expansive soil of Anyang district in Henan improved by Ionic Soil Stabilizer (ISS for short), expansive soil is tested in the compaction and proportiontest. The results show that after mixing the ISS into expansive soil, maximum dry density is significantly increased and its maximum is more than $4.42 \%$ of the original, while the optimum moisture content decreased, while the optimum moisture content decreased; soil particle density of ISS-improved expansive soil have increased and its maximum can reach $2.87 \mathrm{~g} / \mathrm{cm}^{3}$, and it is more than the original of $0.06 \mathrm{~g} / \mathrm{cm}^{3}$, this is an increase of up $2.14 \%$.

\section{Introduction}

Ionic soil stabilizer (ISS for short) is a water-soluble chemical substance composed by multiple strong ions, suitable for soil of different kinds with the clay particle content above $25 \%$. Once it is put into the soil and interacts with soil, combination water of clay minerals can be removed based on electrochemical principle, transforming the soil from hydrophile to hydrophobe, reducing the thickness of clay combination water film and improving the engineering properties of the soil effectively, which includes increased compactness and cut-resistant strength, decreased pore ration and water sensitivity, etc. Reinforcement of soil by ionic soil stabilizer (ISS) is short in circle, low in cost, environment-friendly and harm free to human and stock, avoiding the cost for expensive excavation and fetching materials from different places. Ionic soil stabilizer reinforcement technology offers a method of civil engineering construction characteristic of low cost, convenient construction and material available on the spot, which is applied widely in road, airport, port, water conservancy engineering for soil mass reinforcement. In 1997, the Ministry of Water Conservancy listed ISS as major science and technology popularization project. However, there is few theoretical test research on expansive soil improved by ionic soil stabilizer. Expansive Soil is a special clay, according to ISS for cohesive soils mechanism of action, I try to use the ISS for expansive soil chemically modified, and improved soil were related to physical and mechanical properties test. Found by experiment, ISS can significantly reduce the swell - shrink capacity, improve performance and compressive strength of the soil.

China is a one of a wider distribution of expansive soils country. Expansive soils are mainly distributed in Sichuan, Hubei, Shaanxi, Yunnan, with residual or residual main causes of slope. Expansive soil contains more clay mineral, clay mineral hydrophilic strong sensitivity to water, so expansive soil having swelling, dehydration contraction - and then water - reflation this repeatedly swell - shrink characteristics, and swelling after the intensity decreased greatly, the project poses a significant hazard. ISS is the United States developed an electric ion soil stabilizer. It is mixed with soil after compaction, the clay particles change electric double layer structure by electrochemical principle, the soil can be permanently hydrophilic to hydrophobic, while allowing easy soil compaction, high strength, structural stability of the whole plate is formed. Expansive Soil is a special clay, according to ISS for cohesive soils mechanism of action, I try to use the ISS for expansive soil 
chemically modified, and improved soil were related to physical and mechanical properties test. Found by experiment, ISS can significantly reduce the swell - shrink capacity, improve performance and compressive strength of the soil.

\section{Test materials}

\section{Test soil}

Experimental material is from expansive soil of Anyang. Expansive soil samples containing more tuberculosis matter, gray, hard plastic, soil samples to see more cracks. Expansive undisturbed soil sampling depth of $3 \sim 5 \mathrm{~m}$. The soil samples will be taken back in accordance with the "geotechnical engineering testing procedures" standard, the basic physical and mechanical tests were carried out to obtain test results are shown in Tables 1 and 2.

Table 1 Basic properties of expansive soil

\begin{tabular}{|c|c|c|c|c|c|c|c|c|c|c|}
\hline $\begin{array}{l}\text { nat } \\
\text { con }\end{array}$ & $\begin{array}{l}\text { ral wat } \\
\text { ent } \omega[\%\end{array}$ & & $\begin{array}{l}\text { Natural } \\
\text { density } \\
{\left[\mathrm{g} \cdot \mathrm{cm}^{-3}\right]}\end{array}$ & \multicolumn{2}{|c|}{$\begin{array}{l}\text { proportion } \\
\qquad \triangle \mathrm{s}\end{array}$} & $\begin{array}{c}\text { liquid } \\
\text { limit } \\
\mathrm{W}_{\mathrm{L}}[\%]\end{array}$ & $\begin{array}{c}\text { plastic } \\
\text { limit } \\
\mathrm{W}_{\mathrm{P}}[\%]\end{array}$ & $\begin{array}{c}\text { plastic } \\
\text { index } \\
\mathrm{I}_{\mathrm{P}}[\%]\end{array}$ & \multicolumn{2}{|c|}{$\begin{array}{l}\text { free swelling } \\
\text { ratio Fs[\%] }\end{array}$} \\
\hline & 13.25 & & 2.06 & \multicolumn{2}{|c|}{2.81} & 44.22 & 15.36 & 28.86 & \multicolumn{2}{|c|}{58} \\
\hline \multicolumn{11}{|c|}{ Table 2 Granule composition of expansive soil } \\
\hline \multicolumn{11}{|c|}{ less than a particular size $(\mathrm{mm})$ of the soil mass percentage [\%] } \\
\hline$<10$ & $<5$ & $<2$ & $<1$ & $<0.5$ & $<0$. & $<0.07$ & $<0.05$ & $<0.01$ & $<0.005$ & $<0.002$ \\
\hline 100 & 100 & 98.26 & 94.27 & 90.16 & 89. & 86.34 & 80.05 & 73.31 & 55.23 & 21.47 \\
\hline
\end{tabular}

\section{Curing materials}

Ionic Soil Stabilizer (commonly known as "solid roadbed," "solid Lubao"), is a kind of mixed liquid that contains a number of strong ionic compounds, and it is brown-black water-soluble liquid. Dilute ISS into different concentrations as required. The amount of ISS admixture varies according to different kind of soil, generally the amount of ISS admixture is $0.15 \sim 1 \mathrm{~L}$ per cubic meter of soil volume. When mixed with ISS in the soil, the ISS needs a solution diluted to different concentrations of various proportions watered by volume after dilution ratio, minimum dilution ratio of 1: 400 .

\section{Study on compaction test of ISS-improved expansive soil}

By compaction test to determine the optimum moisture content of the soil and the expansion ISS improving expansive soil and maximum dry density. Test standard light compaction tester, wet soil prepared to take soil samples. After the expansion of the soil when adding ISS, ISS after dilution with water in different volume ratio watered, shake and spill into the soil, mixing evenly, made of different water content of the sample in a plastic bag, sealed 24 hours according to "road test procedures stable inorganic binder material" People's Republic of China (JTJ057-94) standard compaction test, get test results expansive soil compaction and ISS solidified soil are shown in Table 3. It can be drawn from Table 3: Not adding expansive soil ISS maximum dry density of $1.81 \mathrm{~g} / \mathrm{cm}^{3}$, the optimum moisture content of $15.47 \%$; after adding ISS, expansive soils can be increased to maximum dry density $1.89 \mathrm{~g}$ $/ \mathrm{cm}^{3}$, while optimum moisture content can be reduced to $14.86 \%$.

Table 3 compaction test of ISS-improved expansive soil in different matches

\begin{tabular}{|l|c|c|c|c|c|c|c|c|c|}
\hline ISS: water & 0 & $1: 50$ & $1: 100$ & $1: 150$ & $1: 200$ & $1: 250$ & $1: 300$ & $1: 350$ & $1: 400$ \\
\hline $\begin{array}{l}\text { maximum dry } \\
\text { density[g/cm }\end{array}$ & 1.81 & 1.83 & 1.84 & 1.86 & 1.88 & 1.89 & 1.87 & 1.85 & 1.84 \\
\hline $\begin{array}{l}\text { optimum water } \\
\text { content[\%] }\end{array}$ & 15.47 & 15.25 & 15.14 & 14.93 & 14.89 & 14.86 & 14.91 & 14.96 & 15.08 \\
\hline
\end{tabular}


From the test results, after adding ISS, the optimum water content of expansive soil is slightly lower than the optimum moisture content of prime soil, while the maximum dry density is significantly greater than the maximum dry density of prime soil, when ISS solution ratio of 1: 250, the maximum dry density reaches a maximum increase of $4.42 \%$ than the original. This is due to join the ISS soil, water film thickness can be reduced binding clay, so easy to compacted soil, soil particles between the bound more closely, can effectively improve the soil shear strength, density, pressure solidity, reducing the soil void ratio, so in the same compaction function, stabilized soil maximum dry density greater than the maximum dry density of the prime soil, and optimum water rate decreased.

\section{Study on proportion test of ISS-improved expansive soil}

Specific Gravity measuring method using the pycnometer method. Will take back the expansive soil samples were air-dried, crushed and passed through a $5 \mathrm{~mm}$ sieve. When in the soil when adding ISS, the ISS in various volume after Diluted by adding an aqueous solution of different proportions of ISS, the water content in the optimal moisture control, shake and sprinkle evenly into the expansive soil, mixing uniform, sealed 24 hours in a plastic bag, put moisturizer tank stand. After a certain amount of different ISS treated expansive soil, and air-dried according to People's Republic of China Ministry of Water Resources in 1999 issued a "soil test procedures" specific gravity test, bake at $105 \sim 110{ }^{\circ} \mathrm{C} 10$ hours, and placed in the dryer to cool to room temperature the test results obtained are shown in Table 4. Soil particle density of the dry soil particles than the quality of its volume, the same proportion of its value and soil. Different Ratio ISS strengthening expansive soil soil particles density results in Table 2, soil particles density undisturbed expansive soil is $2.81 \mathrm{~g} / \mathrm{cm}^{3}$, ISS after treatment, soil particle density expansive soils can be up to $2.87 \mathrm{~g} / \mathrm{cm}^{3}$, an increase of $0.06 \mathrm{~g} / \mathrm{cm}^{3}$, than the original increase of $2.14 \%$.

Table 4 soil particle density of ISS-improved expansive soil in different matches

\begin{tabular}{|l|c|c|c|c|c|c|c|c|c|}
\hline ISS: water & 0 & $1: 50$ & $1: 100$ & $1: 150$ & $1: 200$ & $1: 250$ & $1: 300$ & $1: 350$ & $1: 400$ \\
\hline $\begin{array}{l}\text { soil particle } \\
\text { density }\left[\mathrm{g} / \mathrm{cm}^{3}\right]\end{array}$ & 2.81 & 2.87 & 2.86 & 2.84 & 2.85 & 2.84 & 2.83 & 2.84 & 2.82 \\
\hline
\end{tabular}

As it can be seen from Table 4, after being treated expansive soil ISS soil particles that are greater than the density of soil particles density undisturbed expansive soil. This is because on the one hand in the expansive soil was added ISS, through a series of physical and chemical reactions, prompting combined aqueous layer was reduced thickness, on the other hand because of the high molecular weight surfactant, adjacent key sections are positively charged, the same the polymer chain may be adjacent soil particles through the polymer chain bridge overlap, forming a network structure, positively charged soil particles and opposite charges attract each other on a long chain, and through a long chain of adjacent soil particles as a single entity, become solid overall structure, it can reduce the volume of soil particles, so the quality remains unchanged under the soil particles, soil particles density increases.

\section{Improving mechanism of ISS}

ISS is a sulfonated oil resin, and it is a combination of a number of strong ionic compounds. It can dissolve in water, and it can dissociate cations and anions. by adding ISS into red clay which primarily is clay, it can replace exchangeable cations adsorbed on the clay surface through physical and chemical functions. Double electrode layer in clay surface changes and thickness of water film reduces. The hydrophily of clay transform into hydrophobicity.Meantime, ISS has a structure of polymer chain so that structure units can be linked to form large aggregates. Connection between particles becomes more tightly, therefor, strength of soil enhances. 
Expansive soil swelling, shrinkage of the underlying causes of loss of soil particles that interact with water, causing expansion and reduce the distance between the soil particles of soil particles of clay minerals in the soil combine lattice expansion and change water film thickness, thereby cause soil volume increase or decrease. Electric double layer theory that the contact surface of soil particles, especially when the interaction between soil and water on the surface of colloidal particles, due to lattice displacement electric double layer can be formed. Particles in an electric double layer adsorption capacity for water molecules in the surrounding clay mineral particles form a surface membrane hydration. Since the combination of a water film thick solid particles "wedge" open, so that the distance between the solid particles is increased, resulting in generation of soil volume expansion. When the medium conditions change, so that the soil water film thinner or disappear, then reduce the distance between the particles, so that the soil volume contraction. In addition, the lattice expansion of montmorillonite clay minerals also contributed to the expansion of the important reasons of soil.

ISS dissociates ions in the water. These ions can replace cations adsorbed on the clay surface, so as to achieve the purpose of soil improvement. Unlike other cementing materials, ISS itself is not combined with soil particles and has regenerative capability. The total amount of ISS does not decrease during it reacts with soils, and its effectiveness will not weakened as time goes on. On the contrary, as long as the soil is moist, its effectiveness will continue and will be permanent and irreversible.

\section{Conclusions}

(1) after mixing the ISS into expansive soil, maximum dry density is significantly increased and its maximum is more than $4.42 \%$ of the original, while the optimum moisture content decreased. When the ratio of ISS solution is $1: 250$, the maximum dry density of soil reaches the maximum 1.89 .

(2) soil particle density of ISS-improved expansive soil have increased and its maximum can reach $2.87 \mathrm{~g} / \mathrm{cm}^{3}$, and it is more than the original of $0.06 \mathrm{~g} / \mathrm{cm}^{3}$, this is an increase of up $2.14 \%$.

\section{Acknowledgements}

This paper was financially supported by the surface project of Hubei Province Natural Science Foundation (2014CFB401). I express my sincere thanks.

\section{References}

[1] Xiang W, Cui D.S, Liu L: Earth Science. Vol. 32 No.3(2007), p.397-402(in Chinese).

[2] Liu Q.B, Xiang W, Zhang W.F et al: Rock and Soil Mechanics. Vol. 30 No.8(2009), p.2286-2290(in Chinese).

[3] Fang Y, Lin T, Tan SL: Soil Mechanics(China University of Geosciences Press, China 2003).

[4] Tan L.R, Kong L.W: Rock and Soil Mechanics. Vol. 26 No.7(2005), p.1009-1013(in Chinese).

[5] Miao L.C, Zhong X.C, Yin Z.Z: Rock and Soil Mechanics. Vol. 20 No.2(1999), p.71-75(in Chinese).

[6] Wang S, Zhang Y.B, Zhuo J.P: Highway. No.7(2005), p.192-194(in Chinese).

[7] Yang S.Y, Liu C.Y: Journal of HeBei University of Technology. Vol. 31 No.5(2002), p.116-118(in Chinese). 